\title{
The key role of a glucagon-like peptide-1 receptor agonist in body fat redistribution
}

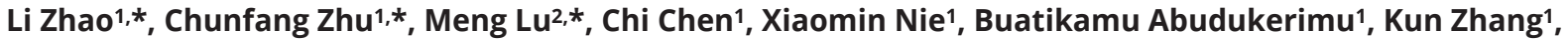 \\ Zhiyuan Ning1, Yi Chen ${ }^{1}$, Jing Cheng1', Fangzhen Xia', Ningjian Wang1, Michael D Jensen ${ }^{3}$ and Yingli Lu1 \\ 1'Institute and Department of Endocrinology and Metabolism, Shanghai Ninth People's Hospital, Shanghai JiaoTong University School of Medicine, \\ Shanghai, China \\ ${ }^{2}$ Research Center for Clinical Medicine, Shanghai Ninth People's Hospital, Shanghai JiaoTong University School of Medicine, Shanghai, China \\ ${ }^{3}$ Endocrine Research Unit, Mayo Clinic, Rochester, Minnesota, USA
}

Correspondence should be addressed to N Wang or M D Jensen or Y Lu: wnj486@126.com or jensen@mayo.edu or luyingli2008@126.com

*(L Zhao, C Zhu and M Lu contributed equally to this work)

\begin{abstract}
Glucagon-like peptide-1 receptor agonists (GLP-1RAs) are an ideal therapy for type 2 diabetes and, as of recently, for obesity. In contrast to visceral fat, subcutaneous fat appears to be protective against metabolic diseases. Here, we aimed to explore whether liraglutide, a GLP-1RA, could redistribute body fat via regulating lipid metabolism in different fat depots. After being fed a high-fat diet for 8 weeks, 50 male Wistar and Goto-Kakizaki rats were randomly divided into a normal control group, a diabetic control group, low- and high-dose liraglutide-treated groups and a diet-control group. Different doses of liraglutide $(400 \mu \mathrm{g} / \mathrm{kg} /$ day or $1200 \mu \mathrm{g} / \mathrm{kg} /$ day $)$ or an equal volume of normal saline were administered to the rats subcutaneously once a day for 12 weeks. Body composition and body fat deposition were measured by dual-energy X-ray absorptiometry and MRI. Isotope tracers were infused to explore lipid metabolism in different fat depots. Quantitative real-time PCR and Western blot analyses were conducted to evaluate the expression of adipose-related genes. The results showed that liraglutide decreased visceral fat and relatively increased subcutaneous fat. Lipogenesis was reduced in visceral white adipose tissue (WAT) but was elevated in subcutaneous WAT. Lipolysis was also attenuated, and fatty acid oxidation was enhanced. The mRNA expression levels of adipose-related genes in different tissues displayed similar trends after liraglutide treatment. In addition, the expression of browning-related genes was upregulated in subcutaneous WAT. Taken together, the results suggested that liraglutide potentially redistributes body fat and promotes browning remodeling in subcutaneous WAT to improve metabolic disorders.
\end{abstract}

\author{
Key Words \\ - glucagon-like peptide-1 \\ - liraglutide \\ - lipid metabolism \\ - diabetes \\ - isotope tracer
}

\section{Introduction}

Type 2 diabetes mellitus (T2DM) is a complex metabolic disorder that is often associated with obesity, dyslipidemia, hypertension, microvascular disease and other complications (American Diabetes Association 2016).
All these complications increase the risk for cardiovascular disease (CVD), which is the major cause of morbidity and mortality in T2DM patients. However, obesity, especially visceral fat obesity, is located 
upstream of T2DM, dyslipidemia and coronary heart disease (Inoue et al. 2014). The distribution of body fat plays an important role in this relationship. The ratio of abdominal to lower-body fat accumulation is a major determinant of adverse metabolic consequences and mortality that is independent of the degree of obesity (McQuaid et al. 2010). Over the past several years, it has been revealed that lower-body fat is not only less harmful than abdominal fat but also provides protection against coronary heart disease and T2DM (Manolopoulos et al. 2010).

Glucagon-like peptide-1 (GLP-1) is an incretin hormone secreted by gastrointestinal L cells in response to oral nutrient ingestion (Wan et al. 2017) and is an ideal therapy for obesity and T2DM (Rajeev \& Wilding 2016). However, native GLP-1 has a short circulating half-life $(t 1 / 2<2 \mathrm{~min})$ that results mainly from rapid enzymatic inactivation by dipeptidyl peptidase-IV (DPP-IV) and/or from rapid kidney clearance (Wan et al. 2017). To prolong the action of GLP-1, DPP-IV inhibitors and GLP-1 receptor agonists (GLP-1RAs) are introduced.

Liraglutide is a GLP-1RA that shares $97 \%$ homology to native GLP-1 and extends the circulating half-life of GLP-1 from 1 to $2 \mathrm{~min}$ to $13 \mathrm{~h}$. A series of Liraglutide Effect and Action in Diabetes (LEAD) studies showed the significant effect of liraglutide on glycemic control and weight reduction, and its long-term efficacy on weight reduction was demonstrated in a subanalysis of the LEAD study (Garber et al. 2011, Nauck et al. 2013) and in other studies (Inoue et al. 2011, Fujishima et al. 2012).

Because GLP-1R activation has been revealed to function in cardiovascular protection (Rizzo et al. 2014), GLP-1RAs are being considered as a promising therapy for both micro- and macro-vascular diseases linked to obese T2DM (Sivertsen et al. 2012). Glycemic control is known to reduce the risk of microvascular complications; however, the macrovascular benefits are less certain (Marso et al. 2016). Thus, GLP-1RAs might protect patients from macrovascular complications by mechanisms other than glycemic control. Many clinical studies have shown that GLP-1RAs improve the lipid profile and blood pressure in patients (Wing et al. 2011, Inoue et al. 2014). However, few studies have investigated whether GLP-1RAs could change body fat distribution by regulating lipid remobilization and turnover in different fat depots. Because visceral fat accumulation and dysfunction are more closely associated with metabolic disorders than is subcutaneous fat, the body fat distributions between visceral and subcutaneous fat, especially lower-body fat, play an important role in the occurrence of metabolic diseases.
The Goto-Kakizaki (GK) rat line is established by repeated inbreeding from a Wistar rat strain selected at the upper limit of normal distribution for glucose tolerance. GK rats are regarded as one of the best available rodent strains for the study of spontaneous T2DM, since the model can offer sufficient commonalities with human T2DM (Portha et al. 2012). Thus, GK rats were chosen in our study to elucidate various types of etiological and pathogenic mechanisms that could also operate in humans.

Based on this information, in the current study, we used liraglutide to explore whether GLP-1RAs could redistribute body fat via regulating lipid metabolism in different fat depots to improve metabolic disorders and macrovascular complications.

\section{Materials and methods}

\section{Animals and experimental design}

Ten male Wistar rats and thirty male GK rats (3 weeks old) were bred and housed locally under a 12/12-h light/darkness cycle in a temperature-controlled room $\left(22 \pm 2^{\circ} \mathrm{C}\right)$ with free access to food and water. After 1 week of acclimation, the animals were all given a high-fat diet (HFD: $40 \%$ carbohydrate, $20 \%$ protein and $40 \%$ fat) (Zhao et al. 2017) for 8 weeks. Then, the animals were randomly divided into four groups and given the high-fat diet continuously for 12 weeks. The groups were formed as follows:

Control group (Wistar+normal saline (NS), $n=10$ ): Wistar rats from the same genetic background as GK rats but with normal glucose levels. The animals were subcutaneously injected with a volume of NS equal to the injection volume in the intervention groups during the 12-week experiment.

Diabetic group $(\mathrm{GK}+\mathrm{NS}, \quad n=10)$ : $\mathrm{GK}$ rats are spontaneous type 2 diabetic rats. In this group, the animals were also subcutaneously injected with an equal volume of NS for 12 weeks.

Low-dose liraglutide (LIRA, Victoza, Novo Nordisk)treated group (GK+LIRA $400 \mu \mathrm{g} / \mathrm{kg} / \mathrm{day}, n=10$ ): The rats were subcutaneously injected with a low dose of LIRA $(400 \mu \mathrm{g} / \mathrm{kg} /$ day) for 12 weeks.

High-dose LIRA-treated group (GK+LIRA $1200 \mu \mathrm{g} / \mathrm{kg}$ / day, $n=10)$ : The rats were subcutaneously injected with a high dose of LIRA (1200 $\mu \mathrm{g} / \mathrm{kg} /$ day) for 12 weeks.

Diet-control group (GK+Diet-control, $n=10)$ : To explore whether the effects of liraglutide on lipid metabolism in various fat depots were different from 
weight change by food restriction, one group of rats was simply food restricted. The rats in this group were fed the same HFD but were restricted to 50\% of the spontaneous food intake (Marcelino et al. 2013) of weight-matched GK controls for 12 weeks.

Body weights and blood glucose levels were measured every 2 weeks. The glucose levels were measured immediately using an electronic glucometer (Terumo, Tokyo, Japan). Lipid profiles, including total cholesterol (TC), triglyceride (TG) and low-density lipoprotein cholesterol (LDL), and insulin levels were assayed at the 0th, 4th and 12th weeks using Siemens Dimension MAX (Siemens Healthcare Diagnostics Inc.). Non-esterified fatty acid (NEFA) levels were determined at the 0th, 4th and 12th weeks using a LabAssay NEFA kit (Wako, Japan). Fasting insulin (FINS) levels were also assayed at the 0th, 4th and 12th weeks using an ELISA kit (Shibayaji, Japan). Then, the homeostatic model assessment index (HOMA-IR) and the insulin sensitivity index (ISI) were calculated from the fasting blood glucose (FBG) and FINS levels using the following formulas: HOMA-IR $=F B G \times F I N S / 22.5$ and $I S I=\ln (1 /(F B G \times F I N S))$ (Zhao et al. 2017). After 12 weeks of treatment, leptin and adiponectin levels were also assayed with ELISA kits (Crystal, USA). The above indicators were assayed in all rats. All experimental procedures were conducted in accordance with the ethical principles for animal research adopted by the Department of Laboratory Animal Science and were approved by the Animal Experimental Ethical Committee of JiaoTong University School of Medicine, Shanghai, China.

\section{Determination of body composition and body fat distribution}

At the end of the experiment, the rats (10 in each group) from the five groups were anesthetized with chloral hydrate $(10 \%, 5 \mathrm{~mL} / \mathrm{kg})$, and body composition was measured by dual-energy X-ray absorptiometry (DXA) (Hologic, Boston, MA, USA). In the DXA results summary, fat mass and total mass were measured, and the ratio of fat to total mass was calculated (Eleftheriades et al. 2016). Body fat deposition was scanned by MRI (MesoMR23-060H-I, Suzhou, China).

\section{Isotope infusion}

All rats were fasted overnight for $8 \mathrm{~h}$ and examined the next morning. For the diet-controlled rats, their fasting time was counted beginning when their food was fully consumed. After local anesthesia with lidocaine, the lateral tail vein was catheterized for the infusion of tracers, and the tail artery was catheterized for blood sampling using previously described methods (Guo \& Zhou 2003). The rats were conscious and relaxed during the whole process of the experiments (Fig. 1A). After the FBG levels returned to baseline (usually within $30 \mathrm{~min}$ ), $\left[\mathrm{U}-{ }^{13} \mathrm{C}\right]$-glycerol $(0.84 \mu \mathrm{mol} / \mathrm{kg} / \mathrm{min}$, Cambridge Isotope, Andover, MA, USA) was constantly infused for $90 \mathrm{~min}$ through the tail vein by a Harvard mini infusion pump (Harvard Apparatus, Holliston, MA, USA). $\left[9,10-{ }^{3} \mathrm{H}\right]$-palmitic acid $(1 \mu \mathrm{Ci}$, PerkinElmer $)$ was also injected through the tail vein at $60 \mathrm{~min}$. During the final $10 \mathrm{~min}$, three arterial blood samples $(0.5 \mathrm{~mL}$ each) used to quantify steady-state glycerol metabolism were collected at 5 -min intervals (Fig. 1B). Then, the animals were killed under anesthesia with pentobarbital $(50 \mathrm{mg} / \mathrm{kg})$. A strip of gastrocnemius muscle (approximately $13 \times 3 \times 1 \mathrm{~mm}$, $50 \mathrm{mg}$ ) was promptly obtained and cultured in vitro to examine the $\beta$-oxidation of $\left[9,10-{ }^{3} \mathrm{H}\right]$-palmitic acid $(1 \mu \mathrm{Ci})$. Other tissues were also quickly harvested, immersed in liquid nitrogen and stored at $-80^{\circ} \mathrm{C}$ for further analysis.
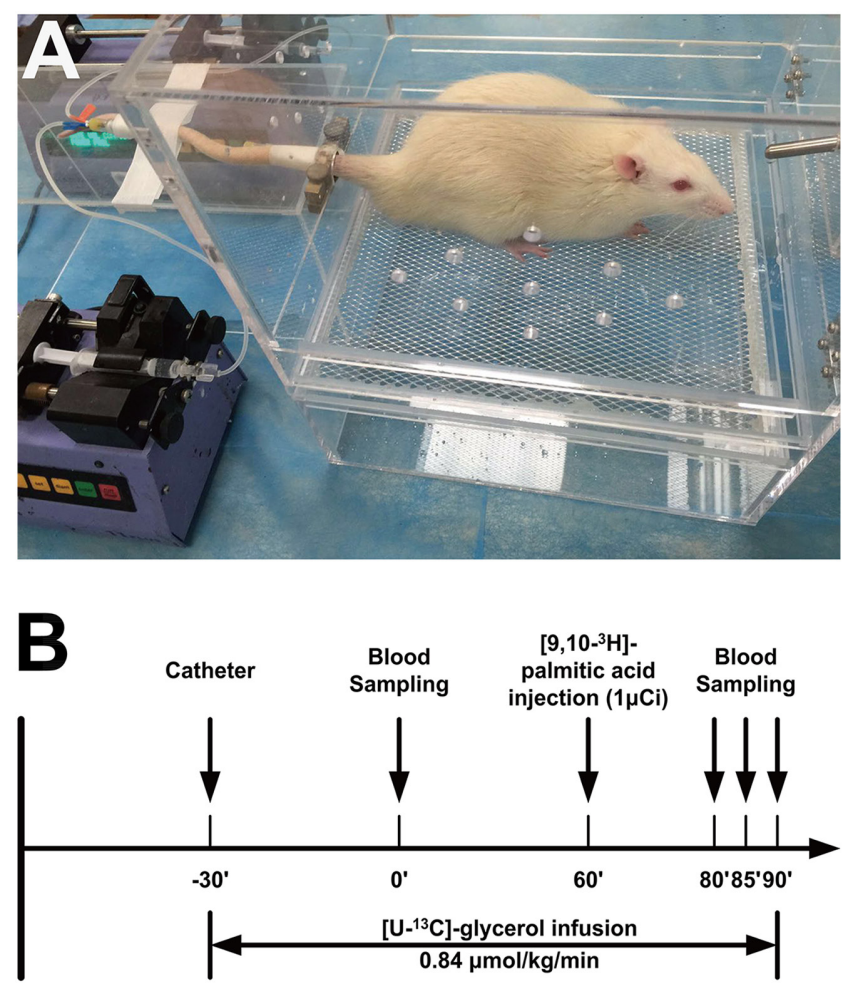

\section{Figure 1}

The platform and protocol for isotope tracer infusion in rats. (A) Experimental setup for tracer infusion. The lateral tail vein was catheterized for tracer infusion, and the tail artery for blood collection. To minimize the experimental stress, all rats were conscious and relaxed, with the ability to groom themselves as normal and drink water freely throughout the experiments. (B) This figure shows the process of tracer infusion and blood collection. 


\section{Measurement of isotope tracers}

The arterial plasma samples were processed with methoxyamine $\mathrm{HCl}$ and BSTFA to obtain the trimethylsilyl derivatives of $\left[\mathrm{U}-{ }^{13} \mathrm{C}\right]$-glycerol. Then, the enrichment of the derivatives was gauged by gas chromatography/ mass spectrometry (GC-MS, Agilent 5975C, Agilent Technologies). Ions with mass-to-charge ratios $(\mathrm{m} / \mathrm{z})$ of 218 (unlabeled glycerol) and 321 (labeled glycerol) were monitored. The 221/218 ratio peak area was calculated, and the corresponding enrichment was determined from standard curves.

Lipids were extracted from the liver and fat tissues using the Folch method (Folch et al. 1957), and TG concentrations were assayed with an ELISA kit (Jiancheng, Nanjing, China). Then, pure TG was isolated using thin layer chromatography (TLC). In addition, ${ }^{3} \mathrm{H}_{2} \mathrm{O}$ generated from the process of $\left[9,10-{ }^{3} \mathrm{H}\right]$-palmitic acid $\beta$-oxidation was obtained by removing the lipids with chloroform. Next, ${ }^{3} \mathrm{H}$ radioactivity from both $\mathrm{TG}$ and ${ }^{3} \mathrm{H}_{2} \mathrm{O}$ was determined using liquid scintillation counting (LS6500 Multipurpose Scintillation Counter, Beckman) as previously described (Zhao et al. 2017).

\section{Calculations}

The appearance rates of glycerol $\left(\mathrm{Ra}_{\mathrm{gly}}\right)$ were calculated with the steady-state equation from the respective tracer infusion rates (F) and mole percent excess (MPE). Lipidosis and lipogenesis in the liver and different fat depots were calculated by dividing the total concentrations of TG or the corresponding tissue mass by the radioactivity of the corresponding labeled TG, respectively (Shadid et al. 2007). Fatty acid $\beta$-oxidation ratios were deduced by measuring the specific activity of ${ }^{3} \mathrm{H}_{2} \mathrm{O}$. All the relative formulas are shown as follows (Vella \& Rizza 2009):

Deposition rate of $\mathrm{TG}(\mathrm{dpm} / \mathrm{g})={ }^{3} \mathrm{H}-\mathrm{TG}$ radioactivity (dpm)/tissue mass (g)

Synthetic rate of TG $(\mathrm{dpm} \times \mathrm{g}$ protein $/ \mathrm{mmol})={ }^{3} \mathrm{H}-\mathrm{TG}$ radioactivity $(\mathrm{dpm}) /$ total $\mathrm{TG}$ concentration $(\mathrm{mmol} / \mathrm{g}$ protein)

$\mathrm{Ra}_{\text {gly }}(\mu \mathrm{mol} / \mathrm{kg} / \mathrm{min})=\mathrm{F}_{\text {gly }}(\mu \mathrm{mol} / \mathrm{kg} / \mathrm{min}) /\left[\mathrm{U}-{ }^{13} \mathrm{C}\right]$-glycerol $\mathrm{MPE}-\mathrm{F}_{\mathrm{gly}}(\mu \mathrm{mol} / \mathrm{kg} / \mathrm{min})$

Fatty acid $\beta$-oxidation ratio $(\%)={ }^{3} \mathrm{H}_{2} \mathrm{O}$ radioactivity $(\mathrm{dpm}) \times$ theoretical muscle mass $(50 \mathrm{mg}) /\left[9,10-{ }^{3} \mathrm{H}\right]-$ palmitic acid radioactivity (dpm)/actual muscle mass $(\mathrm{mg}) \times 100 \%$

\section{Tissue histology}

Liver and adipose tissues (five in each group) were fixed in $4 \%$ paraformaldehyde and sliced after being paraffin embedded on a microtome (SLEE, Germany). Multiple sections were prepared and stained with hematoxylin and eosin (HE) and were analyzed under an optical microscope (CKX41, Olympus) for the morphological changes. Hepatic lipid accumulation was also determined using oil red $\mathrm{O}(\mathrm{ORO})$ staining. ORO staining was viewed using an Axiophot I microscope mounted with an Axiocam color charge-coupled device camera. The intramyocellular TG levels were quantified using Image-Pro software. Additionally, the fat cell sizes at $200 \times$ magnification in different adipose tissues were measured by using ImagePro Plus 6.0 software.

\section{Quantitative real-time PCR}

Total RNA (5 in each group) was extracted from tissues using TRIzol reagent (TaKaRa) following the manufacturer's instructions. cDNA was synthesized using a cDNA Reverse Transcription Kit (TaKaRa). Quantitative real-time PCR was conducted using a LightCycler 96 system (Roche Applied Science) and SYBR Green I as the dsDNA-specific binding dye for continuous fluorescence monitoring. Gene expression was evaluated using the $\Delta \Delta \mathrm{Ct}$ method. $\beta$-Actin was used as the housekeeping gene. The sequences of the gene primers were as follows: monoacylglycerol acyltransferase (Mgat), forward 5'AGG GCA TCT GTG GAG AGC-3' and reverse 5'-GTG GAG AAA GTG GGG AAG GTA CA-3'; diacylglycerol O-acyltransferase 2 (Dgat2), forward 5'-ACA AGC CTA TGC TCA GAC TGG G-3' and reverse 5'-GGA ACA TCC TCA GGG GAA TGC T-3'; hormone-sensitive lipase $(H s l)$, forward 5'-TCC TCT GCT TCT CCC TCT CGT-3' and reverse 5'-GTC CCT GAA TAG GCG CTC ACA-3'; carnitine acyltransferase 1a (Cpt1a), forward 5'-TTG CCG ATG ACG GCT ATG GT-3' and reverse 5'-TGA GTC TGT CTC AGG GCT AGA GA-3'; carnitine acyltransferase 1b (Cpt1b), forward 5'-TTC GGC AAA GGC CTG ATC A-3' and reverse 5'-TTG CCT TTG TCC CGG AAA TG-3'; uncoupling protein-1 (Ucp1), forward 5'-ATC AAA CCC CGC TAC ACT GG-3' and reverse 5'-CAG TAA ATG GCA GGG GAC GT-3'; peroxisome proliferator activated receptor gamma coactivator $1 \alpha(P g c 1 \alpha)$, forward $5^{\prime}$-CAT GCA AAC CAC ACC CAC AG-3' and reverse 5'-CTG AGC AGG GAC GTC TTT GT-3'; bone morphogenetic protein 4 (Bmp4), forward 5'-CAG GGC CAA CAT GTC AGG AT-3' and reverse 5'-TGG CGA CGG CAG TTC TTA TT-3' and 
$\beta$-actin, forward 5'-GCC CCT CTG AAC CCT AAG-3' and reverse 5'-CAT CAC AAT GCC AGT GGT A-3'.

\section{Western blot analysis}

A primary antibody against UCP1 (1:1000) was purchased from Abcam (ab23841), and an antibody against GAPDH (1:1000) was purchased from Biotech Well (WB0197). An HRP-conjugated goat anti-rabbit $\operatorname{IgG}(\mathrm{H}+\mathrm{L})$ was used as the secondary antibody (1:20,000, Jackson). Protein band densities (4 in each group) were quantified using ImageJ.

\section{Statistical analysis}

Data analysis was conducted with IBM SPSS Statistics, version 22 (IBM Corporation). All data were presented as the means \pm standard deviations (s.D.), and statistical significance was assessed by one-way ANOVA (LSD). $P<0.05$ was considered statistically significant.

\section{Results}

\section{Liraglutide-induced weight loss and improved glycemic parameters}

After an 8-week HFD, blood glucose levels and insulin resistance were significantly greater in GK rats than in Wistar rats. After the first injection of liraglutide, the antihyperglycemic effects and weight-sparing effects were observed within the first 2 weeks. Liraglutide treatment significantly decreased the blood glucose levels in both fasting (Fig. 2A) and postprandial (Fig. 2B) states. Food restriction also decreased the glucose levels to those of Wistar rats. Food intake was acutely suppressed by liraglutide within the first week. (Fig. 2C). However, body weight gain was steadily attenuated from the 2 nd week, although food intake was not inhibited by liraglutide as much as in the first week (Fig. 2D). In the GK+Dietcontrol group, food intake was less than that in the liraglutide-treated groups, resulting in more weight loss. Although FINS levels (Fig. 2E) were not significantly decreased after 4 weeks of intervention, improvement in insulin resistance was observed in the two liraglutidetreated groups and GK+Diet-control group. After 12 weeks of intervention, the two liraglutide-treated groups and GK+Diet-control group all showed clear improvements in FINS concentrations, HOMA-IR (Fig. 2F) and ISI (Fig. 2G), compared with the GK+NS group.
In particular, in the GK+LIRA (1200 $\mu \mathrm{g} / \mathrm{kg} /$ day) group, FINS concentrations and HOMA-IR were similar to those in the Wistar + NS group, while ISI was still lower than that of the Wistar + NS group.

\section{Liraglutide improved lipid profiles, leptin and adiponectin levels}

After 4 weeks of intervention, TG and NEFA levels were significantly improved in the liraglutide-treated and GK+Diet-control groups. Compared with the Wistar+NS and $\mathrm{GK}+\mathrm{NS}$ groups, liraglutide treatment dramatically reduced TG, TC and NEFA levels after 12 weeks, and there were no differences between the two liraglutide-treated groups (all $P<0.05$ ). These were also improved in the $\mathrm{GK}+$ Diet-control group, which were comparable with those of the GK+LIRA $(1200 \mu \mathrm{g} / \mathrm{kg} /$ day) group (Fig. 3A, B and D). LDL levels were also decreased at the end of the experiment after high-dose liraglutide treatment or food restriction (Fig. 3C). Additionally, a dramatic reduction in leptin levels (Fig. 3E) and an obvious increase in adiponectin levels (Fig. 3F) were observed from the 4th week of liraglutide intervention. Lower leptin levels and higher adiponectin levels were also observed in the GK+Diet-control group, but adiponectin levels were not increased to the same degree as those of the GK+LIRA $(1200 \mu \mathrm{g} / \mathrm{kg} /$ day) group $(P<0.05$, Fig. $3 \mathrm{E}$ and $\mathrm{F})$.

\section{Liraglutide reduced whole-body fat mass, especially visceral fat mass}

The weight reducing effects of liraglutide were found to be associated with reductions in body fat mass. At the end of the experiment, the body compositions of all the rats were measured with DXA (Fig. 4A). The results showed that the ratios of body fat to total mass in the GK+LIRA $(400 \mu \mathrm{g} / \mathrm{kg} /$ day $)(22.40 \pm 2.12 \%)$, GK $+\mathrm{LIRA}(1200 \mu \mathrm{g} / \mathrm{kg} /$ day) $(21.78 \pm 2.08 \%)$ and GK+Diet-control $(24.36 \pm 2.02 \%)$ groups were significantly lower than those in the Wistar+NS $(52.10 \pm 1.64 \%)$ and GK+NS (38.36 $\pm 3.36 \%)$ groups. There were no significant differences between the three intervention groups (Fig. 4B). Similarly, the total fat mass in GK+LIRA $(400 \mu \mathrm{g} / \mathrm{kg} /$ day) $(85.4 \pm 5.77 \mathrm{~g})$, GK+LIRA $(1200 \mu \mathrm{g} / \mathrm{kg} /$ day $)(78.74 \pm 11.60 \mathrm{~g})$ and GK+ Dietcontrol $(89.96 \pm 4.05 \mathrm{~g})$ groups were significantly lower than that in the Wistar+NS $(256.1 \pm 5.72 \mathrm{~g})$ and GK+NS $(158.86 \pm 15.31 \mathrm{~g})$ groups. Also, no significant differences existed between the three intervention groups. The MRI results revealed that liraglutide treatment considerably 
A

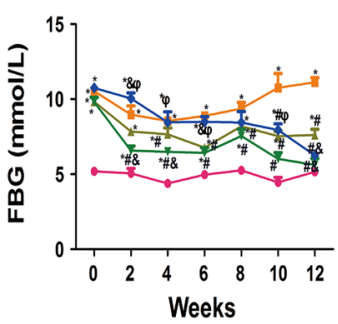

- Wistar+NS $\quad-$ GK+NS

E

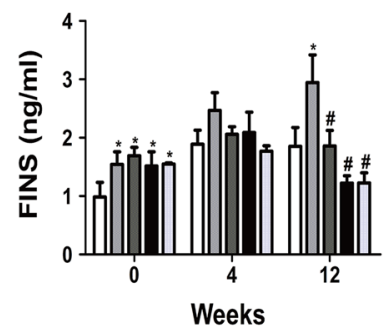

Wistar+NS
B

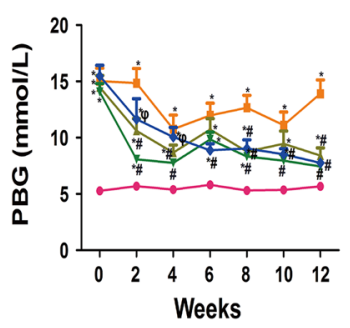

- GK+LIRA $(400 \mu \mathrm{g} / \mathrm{kg} / \mathrm{d})$

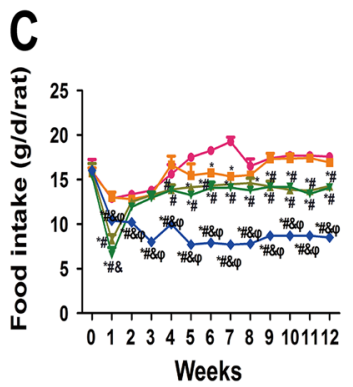

D

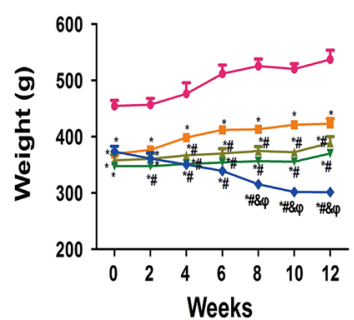

$\rightarrow$ GK+Diet-control

\section{* GK+LIRA $(1200 \mu \mathrm{g} / \mathrm{kg} / \mathrm{d})$}

G

F

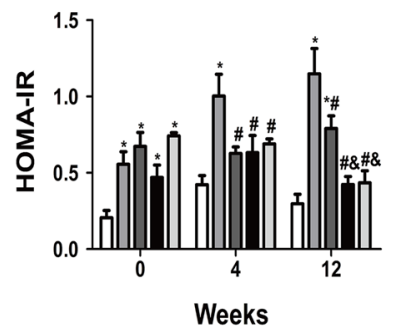

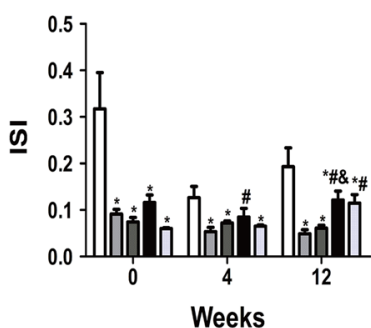

Weeks

GK+LIRA $(400 \mu g / \mathrm{kg} / \mathrm{d})$

GK+LIRA $(1200 \mu \mathrm{g} / \mathrm{kg} / \mathrm{d})$

GK+Diet-control

\section{Figure 2}

Liraglutide attenuated glucose levels, food intake, body weight gain and insulin resistance. (A) Dose-dependent improvement of fasting blood glucose (FBG) levels. (B) Dose-independent improvement of postprandial blood glucose (PBG) levels. (C) Dose-independent inhibition of food intake.

(D) Dose-independent attenuation of body weight gain. (E) Decreases in fasting insulin (FINS) levels. (F) Improvement of insulin resistance. (G) Elevation of insulin sensitivity. The above indicators were assayed in all rats ( $n=10$ in each group). Data are presented as the mean \pm S.E.M. * $P<0.05$, vs Wistar + NS

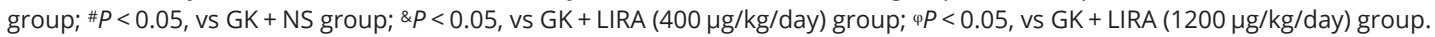

decreased the visceral fat accumulation (Fig. 4C), but the subcutaneous fat accumulation appeared to be slightly increased (Fig. 4D). Interestingly, in the GK+Diet-control group, the visceral fat was not obviously decreased, but the subcutaneous fat was relatively decreased compared with GK+NS group (Fig. 4C and D).

\section{Liraglutide improved hepatic steatosis and reduced adipocyte size in fat depots}

Liraglutide injections or food restriction drastically reduced hepatic lipid accumulation in GK rats (Fig. 5A and $\mathrm{B}$ ). The ratios of the oil red O-stained area to the total area in the liver were significantly lower in the GK+LIRA ( $400 \mu \mathrm{g} / \mathrm{kg} /$ day) $(21.00 \pm 2.58 \%)$, GK+LIRA $(1200 \mu \mathrm{g} / \mathrm{kg} /$ day) $(17.75 \pm 2.75 \%)$ and GK+ Diet-control $(23.00 \pm 2.58 \%)$ groups than in the Wistar + NS $(33.25 \pm 2.75 \%)$ and GK+NS groups $(34.00 \pm 2.94 \%)$ (Fig. $5 \mathrm{C}, P<0.05)$. Although there was no difference between the two liraglutide-treated groups, the hepatic lipid accumulation in the GK+Dietcontrol group was more severe than that in the GK+LIRA $(1200 \mu \mathrm{g} / \mathrm{kg} /$ day $)$ group $(P<0.05)$. Figure $5 \mathrm{D}, \mathrm{E}$ and $\mathrm{F}$ showed the morphological changes of the mesenteric, inguinal and cluneal white adipose tissue (WAT). The cell sizes in all fat depots were smaller in the liraglutidetreated and GK+Diet-control groups (103.33 \pm 3.14 , $96.50 \pm 5.54$ and $98.67 \pm 7.76 \mu \mathrm{m}$, respectively) than in the controls (Wistar+NS: $118.17 \pm 12.59,125.67 \pm 3.78$, $117.83 \pm 3.19 \mu \mathrm{m} ; \mathrm{GK}+\mathrm{NS}$ : $119.00 \pm 8.08, \quad 112.83 \pm 7.49$, $121.00 \pm 3.90 \mu \mathrm{m}, P<0.05)$. There were no differences in cell sizes between the GK+LIRA $(400 \mu \mathrm{g} / \mathrm{kg} /$ day $)(71.67 \pm 3.20$, $84.83 \pm 3.87$ and $101.33 \pm 5.82 \mu \mathrm{m}$, respectively) and GK+LIRA $(1200 \mu \mathrm{g} / \mathrm{kg} /$ day $)(69.17 \pm 4.71,88.67 \pm 5.65$ and $95.83 \pm 5.23 \mu \mathrm{m}$, respectively) groups for all fat depots. However, in the mesenteric WAT and inguinal WAT, the cell sizes were larger in the diet-control group than in the two liraglutide-treated groups $(P<0.05)$.

\section{Liraglutide decreased the deposition and synthetic rates of TG in the liver and mesenteric WAT but increased these rates in the cluneal WAT}

Compared with those in the GK+NS group, the deposition and synthetic rates of TG in the liver and mesenteric 
A

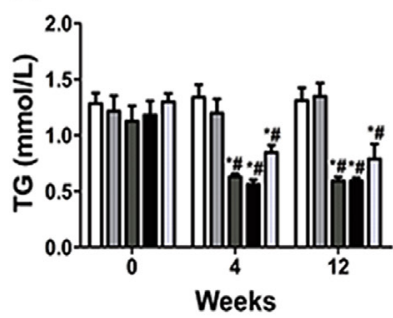

D

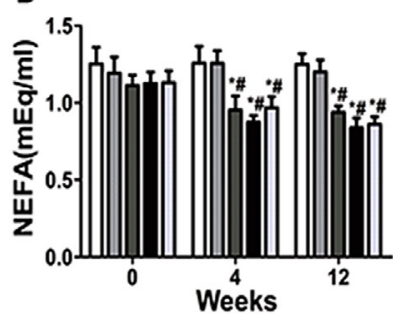

Wistar+NS
B

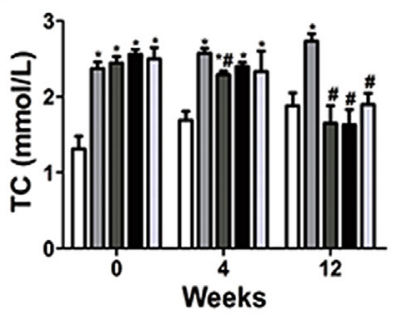

E

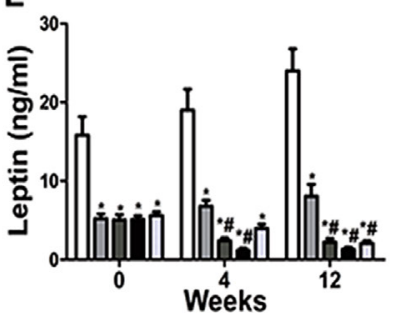

C

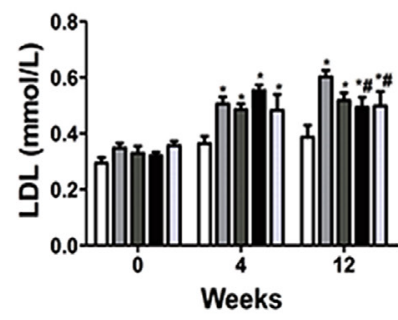

$\mathbf{F}$

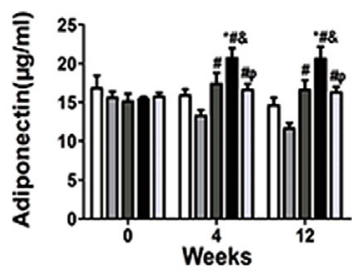

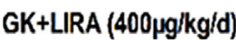

GK+Diet-control

\section{Figure 3}

Liraglutide improved lipid profiles and leptin and adiponectin levels. (A) Triglyceride (TG) levels. (B) Total cholesterol (TC) levels. (C) Low-density lipoprotein-cholesterol (LDL) levels. (D) Non-esterified fatty acid (NEFA) levels. (E) Leptin levels. (F) Adiponectin levels. The above indicators were assayed in all rats $\left(n=10\right.$ in each group). Data are presented as the mean \pm S.E.M. ${ }^{*} P<0.05$, vs Wistar + NS group; $\# P<0.05$, vs GK + NS group; \& $P<0.05$, vs GK + LIRA $\left(400 \mu \mathrm{g} / \mathrm{kg} /\right.$ day) group; $\varphi^{\varphi}<0.05$, vs GK + LIRA $(1200 \mu \mathrm{g} / \mathrm{kg} /$ day) group.

WAT were significantly reduced in the two liraglutidetreated groups, and there were no significant differences between these two groups. In the GK+Diet-control group, although the deposition and synthetic rates of TG were also significantly decreased in the liver compared with those in the GK+NS group, the synthetic rates of TG were higher than those in the GK+LIRA $(1200 \mu \mathrm{g} / \mathrm{kg} / \mathrm{day})$ group $(P<0.05)$. Interestingly, compared with those in the $\mathrm{GK}+\mathrm{NS}$ group, the deposition and synthetic rates of TG in the cluneal WAT were drastically elevated in the two liraglutide-treated groups but not in GK+Diet-control group (Fig. 6A and C). Correspondingly, the ratios of lipid deposition in different fat depots (cluneal/mesenteric) gradually increased in the liraglutide-treated groups but not in GK+Diet-control group (Fig. 6B).

In the inguinal WAT, the change trends were different from those in cuneal WAT. There were no differences in the synthetic rate of TG in the inguinal WAT among the five groups (Fig. 6C). Moreover, the deposition rate of TG was decreased after liraglutide treatment. Nevertheless, the ratios of lipid deposition in different fat depots (inguinal/mesenteric) were still increased in the liraglutide-treated groups. The deposition rate of TG was also decreased by food restriction in the inguinal WAT, so its ratio to that in mesenteric WAT was not different from the controls (Fig. 6A and B). The specific data were shown in Table 1.

\section{Liraglutide decreased lipolysis and promoted fatty acid $\beta$-oxidation in the skeletal muscle}

$\mathrm{Ra}_{\text {gly }}$ in the blood can reflect the extent of lipolysis, as the main source of glycerol is peripheral adipose tissue degradation during fasting (Zhao et al. 2017). After a 12-week intervention, the two liraglutide-treated groups $(0.89 \pm 0.13$ and $0.63 \pm 0.13 \mu \mathrm{mol} / \mathrm{kg} / \mathrm{min})$ and $\mathrm{GK}+$ Dietcontrol group $(0.87 \pm 0.03 \mu \mathrm{mol} / \mathrm{kg} / \mathrm{min})$ all had lower $\mathrm{Ra}_{\text {gly }}$ than the Wistar + NS $(1.4 \pm 0.27 \mu \mathrm{mol} / \mathrm{kg} / \mathrm{min})$ and $\mathrm{GK}+\mathrm{NS}$ $(1.48 \pm 0.78 \mu \mathrm{mol} / \mathrm{kg} / \mathrm{min}$ ) groups (all $P<0.05)$ (Fig. 6D). In contrast, the ratios of fatty acid $\beta$-oxidation in the skeletal muscle were dramatically increased in the liraglutidetreated groups $(10.72 \pm 4.81 \%$ and $16.30 \pm 1.11 \%)$ compared with the GK+NS group $(1.33 \pm 0.42 \%, P<0.05)$, and this effect was drug dose dependent. The ratio of fatty acid $\beta$-oxidation in the GK+Diet-control group $(7.85 \pm 1.16 \%)$ was also augmented compared with that in the GK+NS group, but was lower than that in the Wistar+NS and GK+LIRA (1200 $\mu \mathrm{g} / \mathrm{kg} /$ day) groups. Relative to the GK+NS group, the Wistar+NS group $(11.48 \pm 3.11 \%)$ had a higher ratio of fatty acid $\beta$-oxidation $(P<0.05)$ (Fig. $6 \mathrm{E})$. 


\begin{tabular}{l|l|l|r|r|}
$\begin{array}{l}\text { Journal of } \\
\text { Endocrinology }\end{array}$ & L Zhao, C Zhu, M Lu et al. & $\begin{array}{l}\text { Liraglutide and fat } \\
\text { redistribution }\end{array}$ & $\mathbf{2 4 0 : 2}$ & $\mathbf{2 7 8}$ \\
\hline
\end{tabular}

A

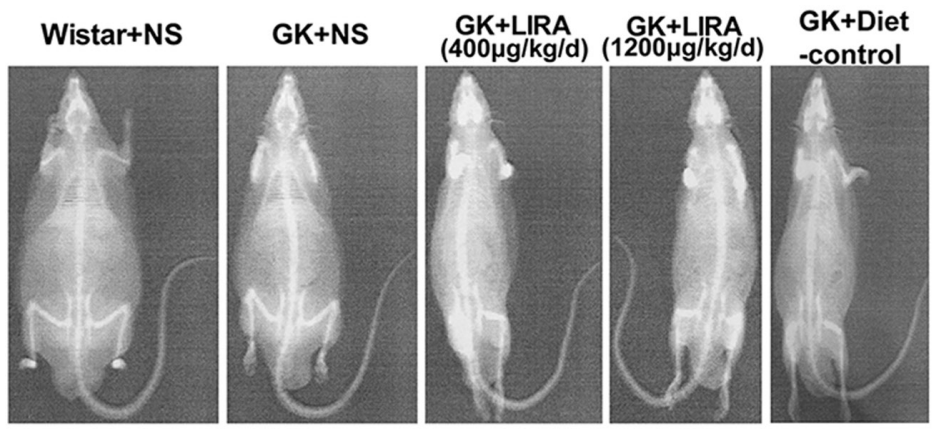

B

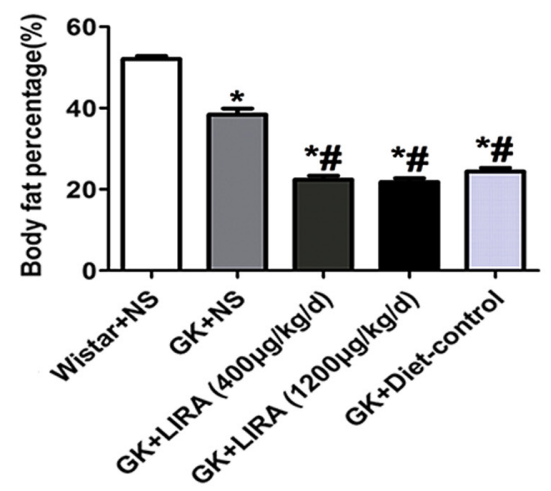

C Visceral WAT (perirenal) Wistar+NS

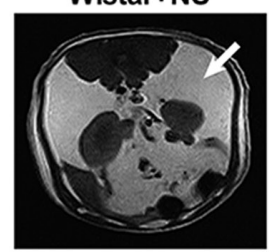

GK+NS

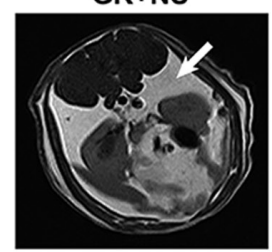

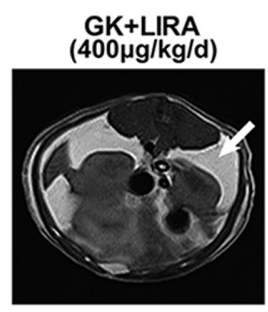
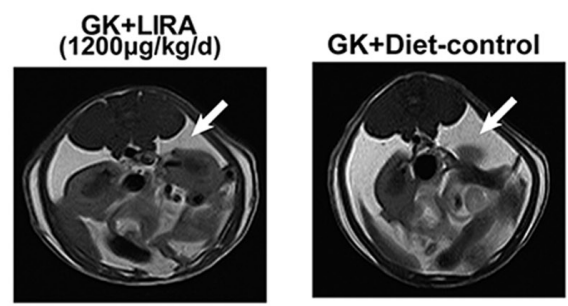

D Subcutaneous WAT (cluneal) Wistar+NS

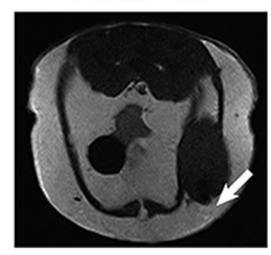
GK+NS

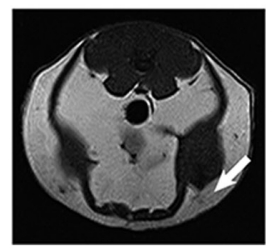

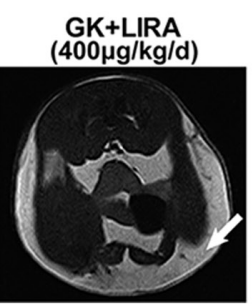
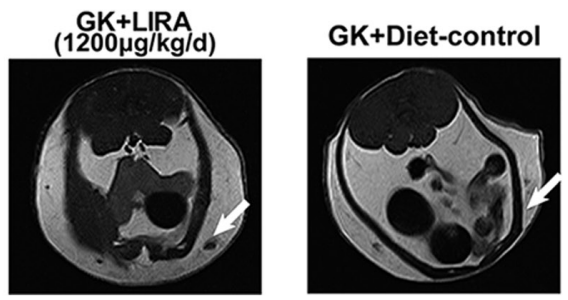

\section{Figure 4}

Liraglutide reduced whole-body fat mass, especially visceral fat mass. (A and B) Reduction in whole-body fat mass. Dual-energy X-ray imaging showed that liraglutide significantly reduced the body fat ratios in a dose-independent manner. (C and D) Images of visceral and subcutaneous fat deposition with magnetic resonance imaging (MRI). Liraglutide considerably decreased visceral fat accumulation, while subcutaneous fat accumulation appeared to be slightly increased in a dose-dependent manner. The above indicators were assayed in all rats ( $n=10$ in each group). * $P<0.05$, vs Wistar + NS group; $\# P<0.05$, vs GK + NS group.

\section{Liraglutide regulated gene expression related to lipid metabolism in the liver and in different fat depots}

To further evaluate the effects of liraglutide on lipid metabolism, the mRNA expression levels of adipose-related genes were investigated by qPCR. Liraglutide treatment significantly downregulated the mRNA expression levels of key enzymes (Mgat and Dgat2) involved in TG synthesis in the liver and mesenteric WAT but upregulated these enzymes in the inguinal and cluneal WAT. Food restriction also downregulated Mgat and Dgat2 expression in the liver but upregulated their expression in inguinal WAT. Besides, Dgat2 was low-expressed in mesenteric WAT and was over-expressed in cluneal WAT by food restriction, but these effects were weaker than those in the high-dose liraglutide group (Fig. 7A and B).
The mRNA expression levels of a key enzyme (Hsl) involved in TG degradation were downregulated by liraglutide and food restriction in both liver and mesenteric WAT. In the mesenteric WAT, the expression of $\mathrm{Hsl}$ was decreased much more in GK+LIRA $(1200 \mu \mathrm{g} / \mathrm{kg} /$ day $)$ group than in GK+Diet-control group. For the subcutaneous WAT, the mRNA expression levels of $\mathrm{Hsl}$ were also downregulated by liraglutide in the cluneal WAT but upregulated in the inguinal WAT. Food restriction also increased the expression of $\mathrm{Hsl}$ in inguinal WAT, but had a weaker effect than did the high dose of liraglutide (Fig. 7C).

Both Cpt1a and Cpt1b are key enzymes involved in fatty acid $\beta$-oxidation. Cpt1a was mainly expressed in the liver and fat tissues, whereas $C p t 1 b$ was expressed in the skeletal muscle. After liraglutide intervention, Cpt1a was over-expressed in the liver, mesenteric and cluneal WAT, 
A Liver HE staining

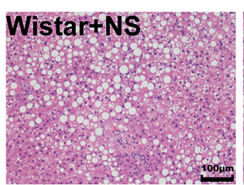

GK+LIRA

$(400 \mu \mathrm{g} / \mathrm{kg} / \mathrm{d})$

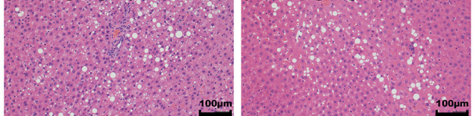

GK+Diet-control

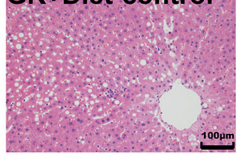

D Mesenteric WAT HE staining Wistar+NS GK+NS
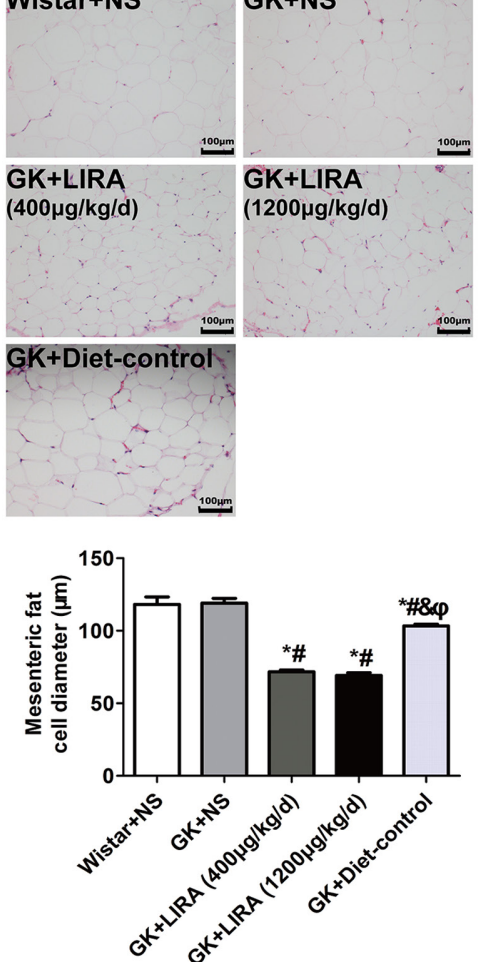

B Liver Oil Red staining
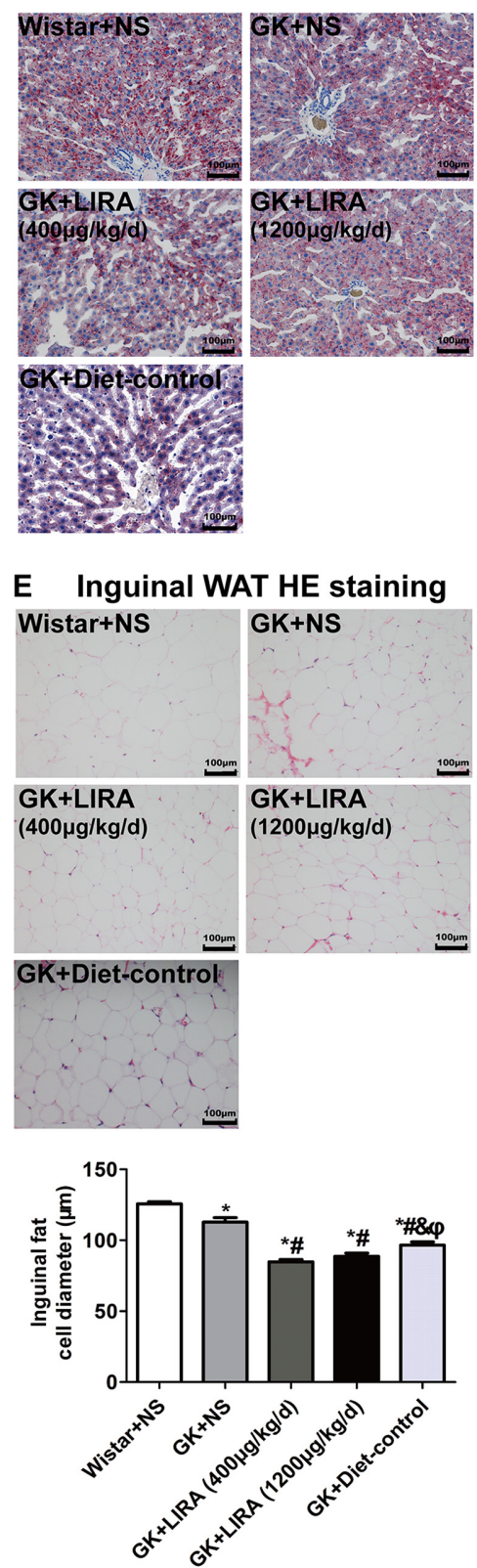

C
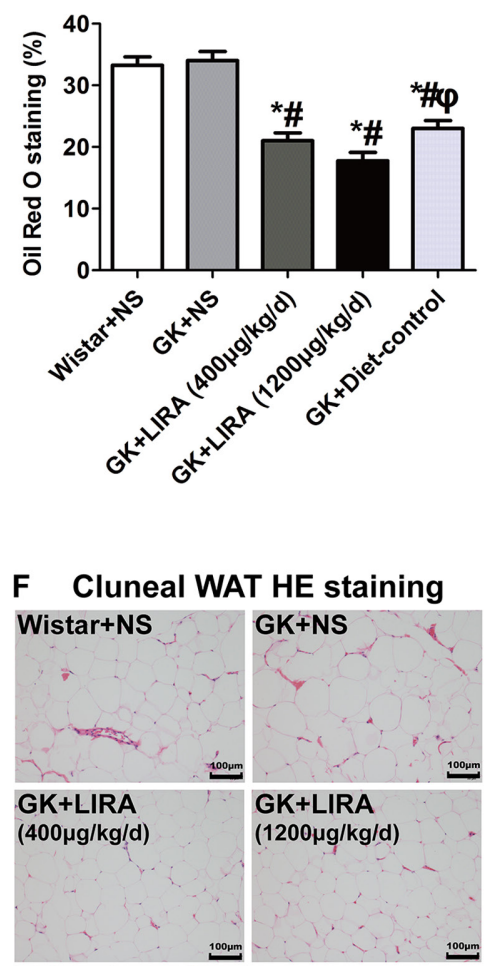

GK+Diet-control
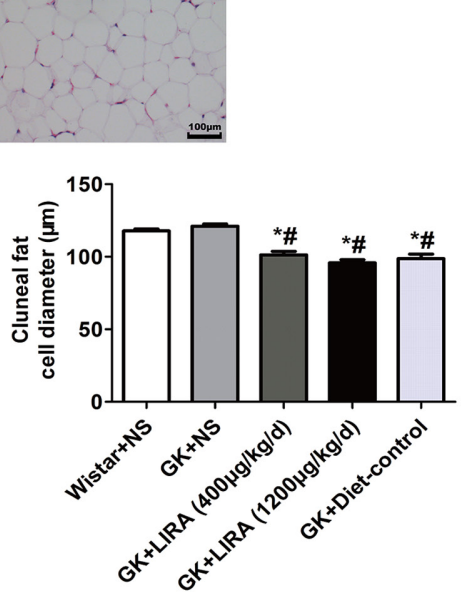

Figure $\mathbf{5}$

Liraglutide improved hepatic steatosis and reduced adipocyte size in different fat depots. (A) HE staining of liver tissues (magnification $\times 200$ ). (B) Oil red $\mathrm{O}$ staining of liver tissues (magnification $\times 200$ ). (C) Area ratios of oil red O staining. Liraglutide or food restriction dramatically decreased ectopic lipid accumulation in the liver after intervention for 12 weeks. (D) HE staining of mesenteric white adipose tissue (WAT) (magnification $\times 200)$. (E) HE staining of inguinal WAT (magnification $\times 200$ ). (F) HE staining of cluneal WAT (magnification $\times 200$ ). Liver or adipose tissues in different fat depots were all randomly chosen from the five groups ( $n=5$ in each group). ${ }^{*} P<0.05$, vs Wistar + NS group; $\# P<0.05$, vs GK + NS group; $\& P<0.05$, vs GK + LIRA (400 $\mu$ g/kg/day) group; $\varphi P<0.05$, vs GK + LIRA $(1200 \mu \mathrm{g} / \mathrm{kg} /$ day $)$ group.

but its expression was reduced in the inguinal WAT. A similar trend in the expression of Cpt1a in the liver and different fat depots was also observed in the GK+Dietcontrol group, but only in the cluneal WAT, there was a significant difference between GK+NS and GK+Dietcontrol groups (Fig. 7D).
The mRNA expression levels of $C p t 1 b$ in the skeletal muscle were also considerably upregulated by the highdose of liraglutide and food restriction. The effect of the high-dose of liraglutide was stronger than that of food restriction (Fig. 7E). Ucp1 was mainly expressed in brown adipose tissue (BAT) and involved in thermogenesis 
A

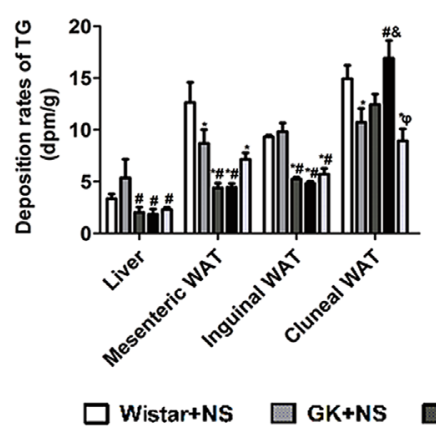

D

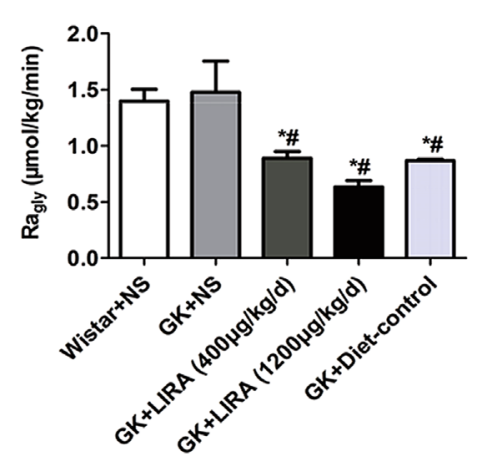

B

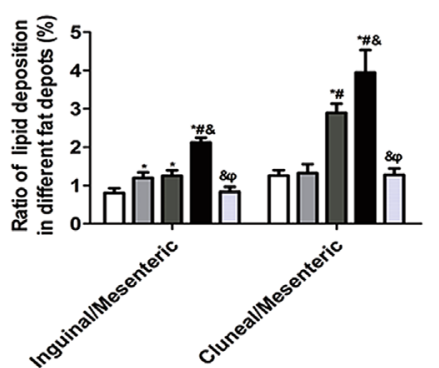

C

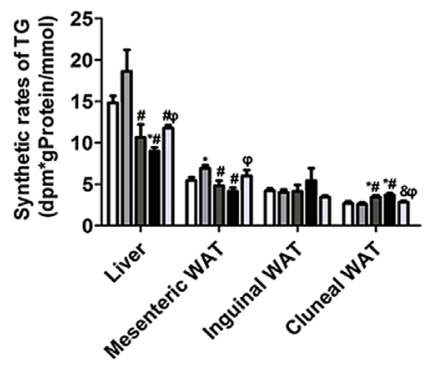

GK+LIRA $(1200 \mu \mathrm{g} / \mathrm{kg} / \mathrm{d})$

GK+Diet-control

E

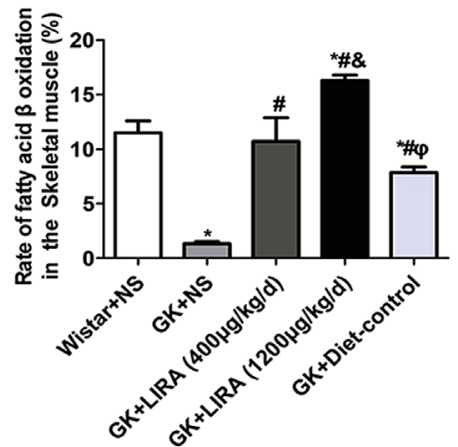

\section{Figure 6}

Liraglutide redistributed visceral and subcutaneous fat deposition by regulating lipid metabolism in different tissues. (A) Deposition rates of TG in different tissues. (B) Ratio of lipid deposition in the subcutaneous white adipose tissue (WAT) to that in the visceral WAT. (C) Triglyceride (TG) synthetic rates in different tissues. (D) Inhibition of lipolysis. (E) Enhancement of fatty acid $\beta$-oxidation in skeletal muscle. The above indicators were assayed in all rats ( $n=10$ in each group). Data are presented as the mean \pm s.E.M. ${ }^{*} P<0.05$, vs Wistar + NS group; $\# P<0.05$, vs GK + NS group; $\& P<0.05$, vs GK + LIRA $(400 \mu \mathrm{g} / \mathrm{kg} /$ day $)$ group; $\varphi P<0.05$, vs GK + LIRA $(1200 \mu \mathrm{g} / \mathrm{kg} /$ day $)$ group.

activation. Bmp4 could induce brown fat-like changes in WAT and increase insulin sensitivity (Qian et al. 2016). WAT browning could be enhanced through the induction of Ucp1 expression and/or mitochondrial oxidative metabolism (Mao et al. 2018). Pgc1 1 , a browning-related gene, was known as a significant regulator of mitochondrial biogenesis, oxidative phosphorylation and fatty acid metabolism (Balampanis et al. 2018). Both liraglutide and food restriction significantly upregulated the mRNA expression levels of Ucp1 in the inguinal and cluneal WAT, and the expression of Ucp1 was increased most by the high-dose of liraglutide (Fig. 7F). However, there were no obvious differences among the five groups in the mesenteric WAT. The expression levels of Pgc1 $($ Fig. 7G) and $B m p 4$ (Fig. $7 \mathrm{H}$ ) mRNA were in line with those of $U c p 1$.

\section{Liraglutide upregulated UCP1 protein expression in the subcutaneous fat depots}

In the BAT, the UCP1 protein expression levels were not significantly different among the five groups after

(C) 2019 Society for Endocrinology Published by Bioscientifica Ltd.
Printed in Great Britain liraglutide intervention and food restriction (Fig. 8A). There were also no significant differences in the mesenteric WAT among these five groups (Fig. 8B). However, the protein expression levels of UCP1 were significantly upregulated by liraglutide in the inguinal and cluneal WAT, an effect that was dose independent. The UCP1 protein expression levels in the subcutaneous WAT were also upregulated in GK+Diet-control group, and were comparable with those in the two liraglutide-treated groups (Fig. 8C and D). This revealed that liraglutide could promote browning remodeling in subcutaneous WAT, and this effect was similar to that of food restriction.

\section{Discussion}

In the current study, we found that liraglutide could decrease the visceral fat deposition but increase subcutaneous (inguinal and cluneal) fat deposition by bi-directionally regulating lipid metabolism in different fat depots, which was revealed by the regulation of the mRNA expression levels of adipose-related genes in 


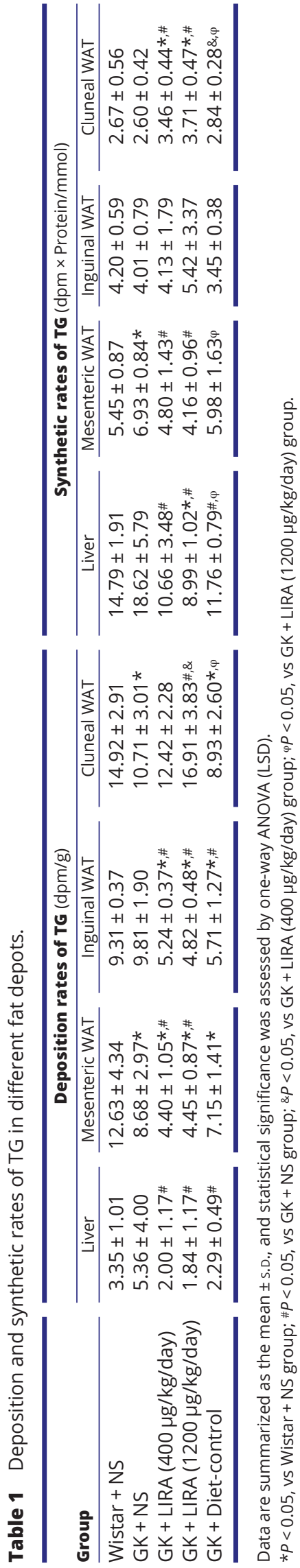

https://joe.bioscientifica.com

(c) 2019 Society for Endocrinology Published by Bioscientifica Ltd.
Printed in Great Britain various tissues. Browning remodeling of the inguinal and cluneal WAT was also found. In addition, improvements in weight gain, blood glucose, lipid profiles, leptin and adiponectin levels, and insulin resistance were observed after liraglutide intervention.

Interestingly, this study indicated for the first time that liraglutide could redistribute body fat by decreasing visceral fat and relatively increasing lowerbody subcutaneous fat deposition, which could partly be attributed to changes in the mRNA expression levels of corresponding key enzymes for lipid metabolism. The major anatomical fat depots include intra-abdominal (omental and mesenteric depots, also termed visceral fat), lower-body (gluteal, subcutaneous leg and intramuscular fat), and upper-body subcutaneous fat (Tchkonia et al. 2013). Upper-body fat (visceral and subcutaneous abdominal) is commonly associated with the unfavorable complications of obesity, while lower-body fat (glutealfemoral) may be protective (White \& Tchoukalova 2014). This is because of their different metabolic and functional properties. Subcutaneous adipocytes were often reported to be smaller than visceral. Dietary fat was stored more efficiently in visceral than in upper- or lower-body subcutaneous fat. Besides, subcutaneous preadipocytes had a greater replicative potential and capacity for adipogenesis. Additionally, visceral fat produced more harmful inflammatory cytokines and adipokines, which would contribute to the metabolic diseases. Genome-wide expression profiles analysis of primary preadipocytes also showed that expression of $>500$ genes varied significantly visceral and subcutaneous fat (Hilton et al. 2015). The effects of GLP-1 analogues on indirectly improving hepatic lipid metabolism have been previously reported most (Parlevliet et al. 2012, Mells \& Anania 2013, Panjwani et al. 2013, Taher et al. 2014, Tanaka et al. 2014, He et al. 2016). Liraglutide has also been shown in many studies to improve hepatic steatosis (Mells \& Anania 2013, Panjwani et al. 2013, Taher et al. 2014) and decrease central fat deposition (Inoue et al. 2011, Fujishima et al. 2012). Additionally, GLP-1RAs had been reported to have the effects on fat redistribution. Morano et al. (2015) reported that a short course of GLP-1RA treatment resulted in a significant decrease in both subcutaneous (peri-umbilical and sub-xiphoid) and visceral (pre-aortic, peri-renal, and epicardial) fat deposits. LEAD-2/3 showed that liraglutide reduced not only visceral adipose tissue but also abdominal subcutaneous adipose tissue (Jendle et al. 2009), since abdominal subcutaneous fat was reported to be independently associated with increased glucose and lipid levels (Lebovitz \& Banerji 2005); however, 
A

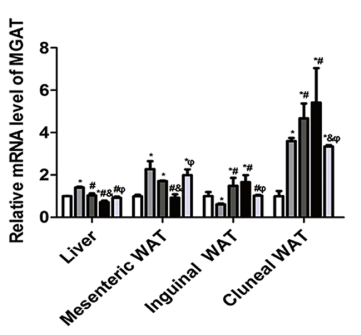

E

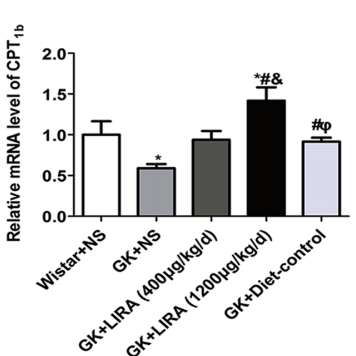

$\square$ Wistar+NS
B

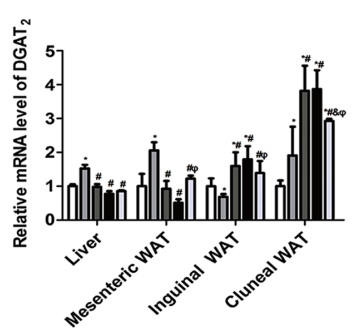

$\mathbf{F}$

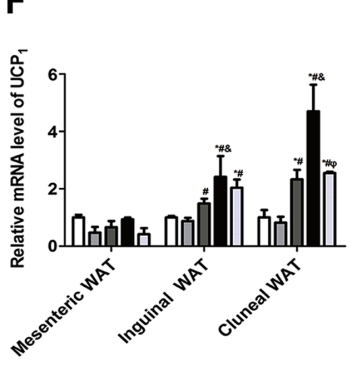

GK+LIRA $(400 \mu g / k g / d)$
C

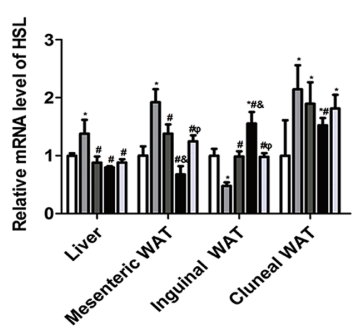

G

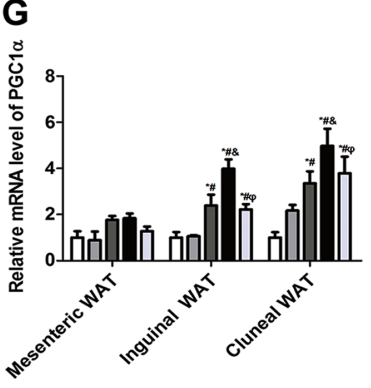

GK+LIRA $(1200 \mu \mathrm{g} / \mathrm{kg} / \mathrm{d})$

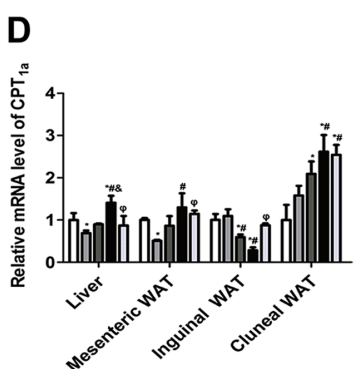

H

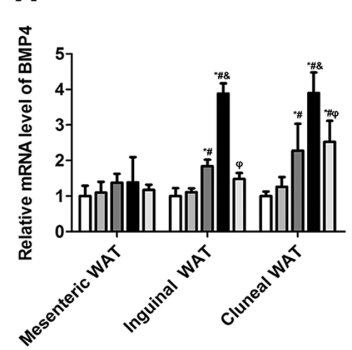

GK+Diet-control

\section{Figure 7}

Liraglutide regulated the mRNA expression levels of genes related to lipid metabolism in different tissues. (A and B) mRNA expression levels of key enzymes (Mgat, Dgat2) involved in triglyceride (TG) synthesis. (C) mRNA expression levels of a key enzyme (Hs/) involved in TG degradation. (D and E) mRNA expression levels of key enzymes (Cpt1a, Cpt1b) for fatty acid $\beta$-oxidation. (F) mRNA expression levels of Ucp 1 in different fat depots. (G) mRNA expression levels of Pgc1 $\alpha$ in different fat depots. (H) mRNA expression levels of Bmp4 in different fat depots. Liver, skeletal muscle or adipose tissues in different fat depots were all randomly chosen from the five groups ( $n=5$ in each group). Data are expressed as the mean \pm S.E.M. $* P<0.05$, vs Wistar + NS

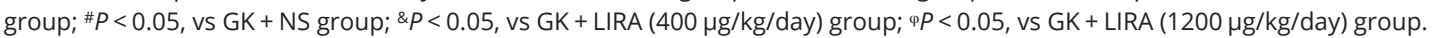

few studies have investigated the effects of liraglutide on lower-body subcutaneous fat. Our study reported for the first time that liraglutide could relatively increase lowerbody subcutaneous fat deposition.

Possible mechanisms involved in the reduction of hepatic fat accumulation after GLP-1RAs intervention include an enhancement of hepatic lipophagy, a reduction in lipid synthesis, VLDL overproduction and lipotoxicity, and a change in hepatocyte enzyme expression levels, which favors a switch in energy utilization from carbohydrate to lipid (Panjwani et al. 2013, Taher et al. 2014). Induction of autophagy via the AMPK/mTOR pathway (Decara et al. 2016) was also reported as one of the possible mechanisms. Other studies demonstrated
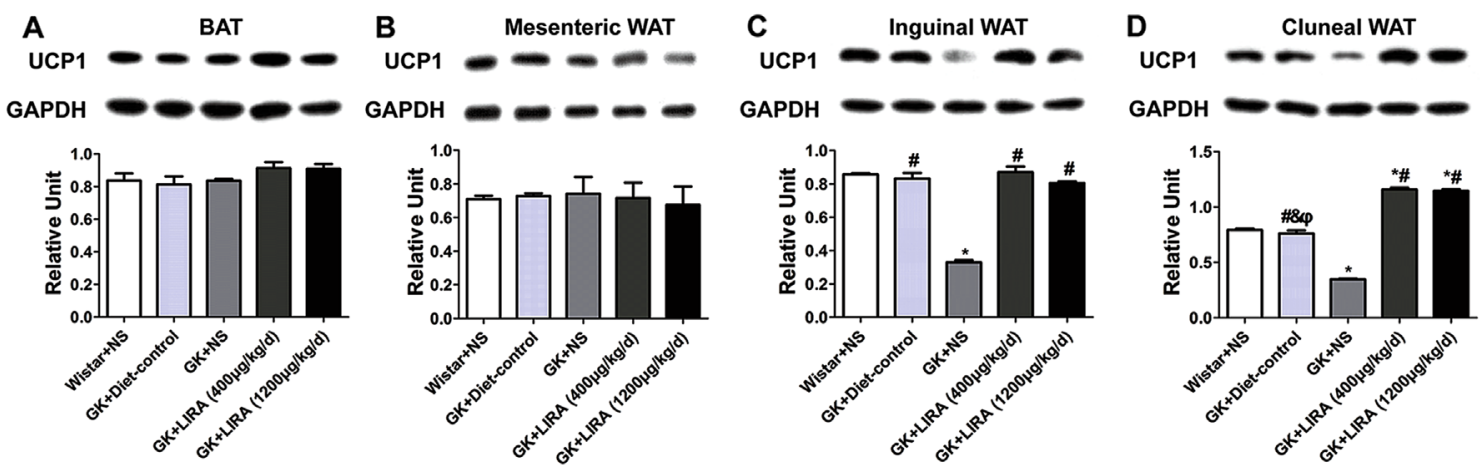

Figure 8

Liraglutide upregulated UCP1 protein expression in the subcutaneous fat depots. There was no significant difference in the UCP1 protein expression levels between the four groups in the brown adipose tissue (BAT) (A) and visceral (mesenteric) white adipose tissue (WAT) (B); however, the UCP1 levels were significantly upregulated in the subcutaneous (inguinal and cluneal) WAT ( $C$ and D) after liraglutide intervention. Adipose tissues in different fat depots were all randomly chosen from the five groups ( $n=4$ in each group). $* P<0.05$, vs Wistar + NS group; $\# P<0.05$, vs GK + NS group; \& $P<0.05$, vs

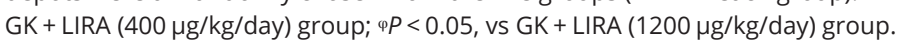


that the decreased hepatic lipid contents in HFD mice were accompanied by a decrease in the expression levels of hepatic lipogenesis genes, while the decreased respiratory exchange ratio was coupled to a reduction in the lipid content in WAT via an upregulation of lipolytic genes (Parlevliet et al. 2012, Tanaka et al. 2014). Part of these effects might also be mediated by the central nervous system, as centrally administered exendin-4 was found to increase peripheral energy utilization and decrease hepatic lipid synthesis (Taher et al. 2014). Since the direct access of liraglutide to the brain is facilitated by the chemical structure of the compound (Lutz \& Osto 2016), the central nervous system may play a partial role in the above effects. Previous study had demonstrated that GLP-1RAs administered in the periphery were stable and highly likely to act on the brain through the humoral and neural pathways. Since GLP-1RAs could remain in the brain for several hours, they could exert effects similar to those induced by the brain-derived endogenous GLP-1 (Katsurada \& Yada 2016). Secher et al. (2014) found that fluorescence-labeled liraglutide administered in the periphery could reach the brain including all circumventricular organs, the zona interna of the median eminence, the area postrema, etc. And liraglutide might exert central effects on increasing feelings of satiety through activating pro-opiomelanocortin neurons and increasing levels of the cocaine- and amphetaminestimulated transcript neuropeptide messenger ribonucleic acid, and on preventing a hunger through increasing agouti-related peptide and neuropeptide Y neuropeptide messenger ribonucleic acid (Knudsen et al. 2016). In our study, the corresponding key enzymes of lipid metabolism in different tissues also changed after liraglutide treatment. In contrast to previous studies, the expression levels of genes related to lipogenesis and lipolysis were downregulated in the liver and visceral WAT but upregulated in the subcutaneous WAT. This may be attributed to the different types of GLP-1RAs, animal species and different lengths of treatment among studies. Further investigations are needed to explore the exact reason.

Another interesting finding was that liraglutide induced subcutaneous WAT browning but not visceral WAT browning. Generally, due to their different effects on metabolic homeostasis, visceral fat is considered 'bad fat' (Bouchi et al. 2017), whereas subcutaneous fat and BAT are considered 'good fat' (Hocking et al. 2013). WAT is mainly responsible for energy storage, and BAT is mainly responsible for dissipating chemical energy in the form of heat (Wu et al. 2015). Recent studies suggest that WAT can present brown-like features in response to certain stimuli and therefore exert an energy-disposal capacity characterized by upregulation of the BATspecific gene Ucp1 (Wu et al. 2015, Jeremic et al. 2017). A previous study revealed that central GLP-1 administration decreased lipid storage in WAT and stimulated adipocyte browning by modulating AMPK in the ventromedial nucleus (VMH), an effect that was accompanied by substantial weight loss (Beiroa et al. 2014). AMPK is considered to be the principal energy sensor in eukaryotic cells and hypothalamic AMPK plays a major role in the central control of food intake by mediating the effects of peripheral nutritional and hormonal stimuli (Lopez et al. 2016). Central administration of GLP-1RAs decreases fatty acid accumulation in WAT, stimulates PGC1 $\alpha / \mathrm{UCP} 1$ related thermogenesis in BAT and increases the uptake of plasma triacylglycerol-derived fatty acids by BAT and WAT actions mediated by inhibition of hypothalamic AMPK phosphorylation and increases in sympathetic outflow (Lockie et al. 2012, Kooijman et al. 2015, Lopez et al. 2015). However, intraperitoneal injection of a GLP-1RA was found to upregulate the expression of Ucp1 in subcutaneous WAT but did not significantly change the expression of Ucp1 in BAT and visceral WAT (Wan et al. 2017). Our study showed a similar trend with the latter, although liraglutide was subcutaneously administered. This finding implies that different routes of drug administration can influence the effects of GLP-1RAs on lipid metabolism in different fat depots, which needs further investigation.

It is important to note that liraglutide treatment elicited a general shift to smaller adipocyte sizes in all white adipose depots, which was consistent with the results of a previous report (Wan et al. 2017). The size of adipocytes can, to a certain extent, reflect the metabolic function of adipocytes (Wan et al. 2017). Although there is controversy about the harmful range of adipocyte sizes (Verhoef et al. 2013), it is generally accepted that the conversion of small adipocytes to large ones is closely related to metabolic diseases. In addition, an increase in the number of small adipocytes can promote lipid metabolism and insulin sensitivity (Wan et al. 2017). Our study revealed that adipocyte sizes were reduced after intervention, partly explaining the anti-obesity effects of liraglutide.

Liraglutide was found to have extra protective effects on regulating lipid metabolism in different fat depots compared with food restriction. Calorie restriction is one 
of the basic ways to improve glucose and lipid metabolism disorders. In our study, food restriction reduced glucose levels and weight gain, and improved insulin resistance and lipid profiles. These effects were all also elicited by liraglutide. In the current study, food restriction also decreased the TG deposition in the liver and inguinal WAT, but did not increase TG deposition in the cluneal WAT. However, TG deposition in the mesenteric WAT was not attenuated by food restriction. Correspondingly, the ratios of fat deposition in the subcutaneous WAT to that in the visceral WAT were not augmented. Advantages of liraglutide included that it not only decreased visceral (liver and mesenteric) fat accumulation, but also increased cluneal fat accumulation. Even in the inguinal WAT, fat deposition was increased relative to that in the mesenteric WAT, after liraglutide treatment. This means that, to some extent, liraglutide affected body fat redistribution.

In conclusion, in the present study, we demonstrated that the long-lasting GLP-1RA liraglutide redistributed body fat through tissue-specific modulation of lipid metabolism in different fat depots, an effect that was different from the effects of simple food restriction on improving lipid metabolism disorders. This effect was associated with the regulation of key enzymes related to lipid metabolism in various tissues. Moreover, liraglutide indirectly regulated fat depot function by reducing the size of adipocytes and stimulating subcutaneous WAT browning. T2DM-related metabolic disorders, which are also risk factors for macrovascular complications, were all improved by liraglutide treatment. These findings provide us with a novel understanding of the anti-obesity action of liraglutide. Liraglutide may protect against macrovascular complications in T2DM patients via a mechanism that is independent of glycemic control.

\section{Declaration of interest}

The authors declare that there is no conflict of interest that could be perceived as prejudicing the impartiality of the research reported.

\section{Funding}

This study was supported by National Natural Science Foundation of China (81570726, 81600609); Shanghai JiaoTong University School of Medicine (2014); Science and Technology Commission of Shanghai Municipality (16411971200, 16410723200); Commission of Health and Family Planning of Pudong District (PW2015D-5); the Fourth Round of Three-Year Public Health Action Plan of Shanghai by the Shanghai Municipal Commission of Health and Family Planning (15GWZK0202, 20164Y0079); Municipal Human Resources Development Program for Outstanding Young Talents in Medical and Health Sciences in Shanghai (2017YQ053); Clinical Research Plan of SHDC (16CR3076B).

(c) 2019 Society for Endocrinology Published by Bioscientifica Ltd. Printed in Great Britain

\section{Author contribution statement}

Y L designed the study; $L Z, C Z, M L, C C, X N, A B, K Z, Z$ N, J C and $\mathrm{F} X$ performed the experiments; $\mathrm{L} Z$ and $\mathrm{N} \mathrm{W}$ analyzed the data and interpreted the results of the experiments; $L Z$ prepared the figures and wrote the manuscript; $Y \mathrm{~L}, J \mathrm{M}$ and $\mathrm{N} W$ edited and revised the manuscript. All authors read and approved the final manuscript.

\section{References}

American Diabetes Association 2016 Introduction. Diabetes Care 39 (Supplement 1) S1-S2. (https://doi.org/10.2337/dc16-S001)

Balampanis K, Chasapi A, Kourea E, Tanoglidi A, Hatziagelaki E, Lambadiari V, Dimitriadis G, Lambrou GI, Kalfarentzos F, Melachrinou M, et al. 2018 Inter-tissue expression patterns of the key metabolic biomarker Pgc1a in severely obese individuals: implication in obesity-induced disease. Hellenic Journal of Cardiology [epub]. (https://doi.org/10.1016/j.hjc.2018.08.002)

Beiroa D, Imbernon M, Gallego R, Senra A, Herranz D, Villarroya F, Serrano M, Ferno J, Salvador J, Escalada J, et al. 2014 GLP-1 agonism stimulates brown adipose tissue thermogenesis and browning through hypothalamic AMPK. Diabetes 63 3346-3358. (https://doi. org/10.2337/db14-0302)

Bouchi R, Nakano Y, Fukuda T, Takeuchi T, Murakami M, Minami I, Izumiyama H, Hashimoto K, Yoshimoto T \& Ogawa Y 2017 Reduction of visceral fat by liraglutide is associated with ameliorations of hepatic steatosis, albuminuria, and microinflammation in type 2 diabetic patients with insulin treatment: a randomized control trial. Endocrine Journal 64 269-281. (https://doi. org/10.1507/endocrj.EJ16-0449)

Decara J, Arrabal S, Beiroa D, Rivera P, Vargas A, Serrano A, Pavon FJ, Ballesteros J, Dieguez C, Nogueiras R, et al. 2016 Antiobesity efficacy of GLP-1 receptor agonist liraglutide is associated with peripheral tissue-specific modulation of lipid metabolic regulators. Biofactors $\mathbf{4 2}$ 600-611. (https://doi.org/10.1002/biof.1295)

Eleftheriades M, Vafaei H, Dontas I, Vaggos G, Marinou K, Pervanidou P, Sebire NJ, Chrousos GP \& Nicolaides KH 2016 Assessment of body composition in Wistar rat offspring by DXA in relation to prenatal and postnatal nutritional manipulation. Pediatric Research 80 319-325. (https://doi.org/10.1038/pr.2016.61)

Folch J, Lees M \& Sloane Stanley GH 1957 A simple method for the isolation and purification of total lipides from animal tissues. Journal of Biological Chemistry 226 497-509.

Fujishima Y, Maeda N, Inoue K, Kashine S, Nishizawa H, Hirata A, Kozawa J, Yasuda T, Okita K, Imagawa A, et al. 2012 Efficacy of liraglutide, a glucagon-like peptide-1 (GLP-1) analogue, on body weight, eating behavior, and glycemic control, in Japanese obese type 2 diabetes. Cardiovascular Diabetology 11 107. (https://doi. org/10.1186/1475-2840-11-107)

Garber A, Henry RR, Ratner R, Hale P, Chang CT, Bode B \& Group LS 2011 Liraglutide, a once-daily human glucagon-like peptide 1 analogue, provides sustained improvements in glycaemic control and weight for 2 years as monotherapy compared with glimepiride in patients with type 2 diabetes. Diabetes, Obesity and Metabolism 13 348-356. (https://doi.org/10.1111/j.1463-1326.2010.01356.x)

Guo Z \& Zhou L 2003 Dual tail catheters for infusion and sampling in rats as an efficient platform for metabolic experiments. Lab Animal 32 45-48. (https://doi.org/10.1038/laban0203-45)

He Q, Sha S, Sun L, Zhang J \& Dong M 2016 GLP-1 analogue improves hepatic lipid accumulation by inducing autophagy via AMPK/mTOR pathway. Biochemical and Biophysical Research Communications 476 196-203. (https://doi.org/10.1016/j.bbrc.2016.05.086)

Hilton C, Karpe F \& Pinnick KE 2015 Role of developmental transcription factors in white, brown and beige adipose tissues. Biochimica et Biophysica Acta 1851 686-696. (https://doi.org/10.1016/j. bbalip.2015.02.003) 
Hocking S, Samocha-Bonet D, Milner KL, Greenfield JR \& Chisholm DJ 2013 Adiposity and insulin resistance in humans: the role of the different tissue and cellular lipid depots. Endocrine Reviews 34 463-500. (https://doi.org/10.1210/er.2012-1041)

Inoue K, Maeda N, Kashine S, Fujishima Y, Kozawa J, Hiuge-Shimizu A, Okita K, Imagawa A, Funahashi T \& Shimomura I 2011 Shortterm effects of liraglutide on visceral fat adiposity, appetite, and food preference: a pilot study of obese Japanese patients with type 2 diabetes. Cardiovascular Diabetology 10 109. (https://doi. org/10.1186/1475-2840-10-109)

Inoue K, Maeda N, Fujishima Y, Fukuda S, Nagao H, Yamaoka M, Hirata A, Nishizawa H, Funahashi T \& Shimomura I 2014 Long-term impact of liraglutide, a glucagon-like peptide-1 (GLP-1) analogue, on body weight and glycemic control in Japanese type 2 diabetes: an observational study. Diabetology and Metabolic Syndrome 6 95. (https:// doi.org/10.1186/1758-5996-6-95)

Jendle J, Nauck MA, Matthews DR, Frid A, Hermansen K, During M, Zdravkovic M, Strauss BJ, Garber AJ \& LEAD-2 and LEAD-3 Study Groups 2009 Weight loss with liraglutide, a once-daily human glucagon-like peptide-1 analogue for type 2 diabetes treatment as monotherapy or added to metformin, is primarily as a result of a reduction in fat tissue. Diabetes, Obesity and Metabolism 11 1163-1172. (https://doi.org/10.1111/j.1463-1326.2009.01158.x)

Jeremic N, Chaturvedi P \& Tyagi SC 2017 Browning of white fat: novel insight into factors, mechanisms, and therapeutics. Journal of Cellular Physiology 232 61-68. (https://doi.org/10.1002/jcp.25450)

Katsurada K \& Yada T 2016 Neural effects of gut- and brain-derived glucagon-like peptide-1 and its receptor agonist. Journal of Diabetes Investigation 7 (Supplement 1) 64-69. (https://doi.org/10.1111/ jdi.12464)

Knudsen LB, Secher A, Hecksher-Sorensen J \& Pyke C 2016 Long-acting glucagon-like peptide-1 receptor agonists have direct access to and effects on pro-opiomelanocortin/cocaine- and amphetaminestimulated transcript neurons in the mouse hypothalamus. Journal of Diabetes Investigation 7 (Supplement 1) 56-63. (https://doi. org/10.1111/jdi.12463)

Kooijman S, Wang Y, Parlevliet ET, Boon MR, Edelschaap D, Snaterse G, Pijl H, Romijn JA \& Rensen PC 2015 Central GLP-1 receptor signalling accelerates plasma clearance of triacylglycerol and glucose by activating brown adipose tissue in mice. Diabetologia 58 2637-2646. (https://doi.org/10.1007/s00125-015-3727-0)

Lebovitz HE \& Banerji MA 2005 Point: visceral adiposity is causally related to insulin resistance. Diabetes Care 28 2322-2325. (https://doi. org/10.2337/diacare.28.9.2322)

Lockie SH, Heppner KM, Chaudhary N, Chabenne JR, Morgan DA, Veyrat-Durebex C, Ananthakrishnan G, Rohner-Jeanrenaud F, Drucker DJ, DiMarchi R, et al. 2012 Direct control of brown adipose tissue thermogenesis by central nervous system glucagon-like peptide-1 receptor signaling. Diabetes 61 2753-2762. (https://doi. org/10.2337/db11-1556)

Lopez M, Dieguez C \& Nogueiras R 2015 Hypothalamic GLP-1: the control of BAT thermogenesis and browning of white fat. Adipocyte $\mathbf{4}$ 141-145. (https://doi.org/10.4161/21623945.2014.983752)

Lopez M, Nogueiras R, Tena-Sempere M \& Dieguez C 2016 Hypothalamic AMPK: a canonical regulator of whole-body energy balance. Nature Reviews Endocrinology 12 421-432. (https://doi.org/10.1038/ nrendo.2016.67)

Lutz TA \& Osto E 2016 Glucagon-like peptide-1, glucagon-like peptide-2, and lipid metabolism. Current Opinion in Lipidology 27 257-263. (https://doi.org/10.1097/MOL.0000000000000293)

Manolopoulos KN, Karpe F \& Frayn KN 2010 Gluteofemoral body fat as a determinant of metabolic health. International Journal of Obesity $\mathbf{3 4}$ 949-959. (https://doi.org/10.1038/ijo.2009.286)

Mao L, Lei J, Schoemaker MH, Ma B, Zhong Y, Lambers TT, Van Tol EAF, Zhou Y, Nie T \& Wu D 2018 Long-chain polyunsaturated fatty acids and extensively hydrolyzed casein-induced browning in a Ucp-1 reporter mouse model of obesity. Food and Function 9 2362-2373 (https://doi.org/10.1039/C7FO01835E)

Marcelino H, Veyrat-Durebex C, Summermatter S, Sarafian D, MilesChan J, Arsenijevic D, Zani F, Montani JP, Seydoux J, Solinas G, et al. $2013 \mathrm{~A}$ role for adipose tissue de novo lipogenesis in glucose homeostasis during catch-up growth: a Randle cycle favoring fat storage. Diabetes 62 362-372. (https://doi.org/10.2337/db12-0255)

Marso SP, Daniels GH, Brown-Frandsen K, Kristensen P, Mann JF, Nauck MA, Nissen SE, Pocock S, Poulter NR, Ravn LS, et al. 2016 Liraglutide and cardiovascular outcomes in type 2 diabetes. New England Journal of Medicine 375 311-322. (https://doi.org/10.1056/ NEJMoa1603827)

McQuaid SE, Humphreys SM, Hodson L, Fielding BA, Karpe F \& Frayn KN 2010 Femoral adipose tissue may accumulate the fat that has been recycled as VLDL and nonesterified fatty acids. Diabetes $\mathbf{5 9}$ 2465-2473. (https://doi.org/10.2337/db10-0678)

Mells JE \& Anania FA 2013 The role of gastrointestinal hormones in hepatic lipid metabolism. Seminars in Liver Disease 33 343-357. (https://doi.org/10.1055/s-0033-1358527)

Morano S, Romagnoli E, Filardi T, Nieddu L, Mandosi E, Fallarino M, Turinese I, Dagostino MP, Lenzi A \& Carnevale V 2015 Shortterm effects of glucagon-like peptide 1 (GLP-1) receptor agonists on fat distribution in patients with type 2 diabetes mellitus: an ultrasonography study. Acta Diabetologica 52 727-732. (https://doi. org/10.1007/s00592-014-0710-z)

Nauck M, Frid A, Hermansen K, Thomsen AB, During M, Shah N, Tankova T, Mitha I \& Matthews DR 2013 Long-term efficacy and safety comparison of liraglutide, glimepiride and placebo, all in combination with metformin in type 2 diabetes: 2-year results from the LEAD-2 study. Diabetes, Obesity and Metabolism 15 204-212. (https://doi.org/10.1111/dom.12012)

Panjwani N, Mulvihill EE, Longuet C, Yusta B, Campbell JE, Brown TJ, Streutker C, Holland D, Cao X, Baggio LL, et al. 2013 GLP-1 receptor activation indirectly reduces hepatic lipid accumulation but does not attenuate development of atherosclerosis in diabetic male ApoE(-/-) mice. Endocrinology 154 127-139. (https://doi.org/10.1210/en.20121937)

Parlevliet ET, Wang Y, Geerling JJ, Schroder-Van der Elst JP, Picha K, O'Neil K, Stojanovic-Susulic V, Ort T, Havekes LM, Romijn JA, et al. 2012 GLP-1 receptor activation inhibits VLDL production and reverses hepatic steatosis by decreasing hepatic lipogenesis in high-fat-fed APOE*3-Leiden mice. PLoS ONE 7 e49152. (https://doi. org/10.1371/journal.pone.0049152)

Portha B, Giroix MH, Tourrel-Cuzin C, Le-Stunff H \& Movassat J 2012 The GK rat: a prototype for the study of non-overweight type 2 diabetes. Methods in Molecular Biology 933 125-159.

Qian SW, Liu Y, Wang J, Nie JC, Wu MY, Tang Y, Zhao YX, Li X, Huang HY, Guo L, et al. 2016 BMP4 cross-talks with estrogen/ERalpha signaling to regulate adiposity and glucose metabolism in females. EBioMedicine $\mathbf{1 1}$ 91-100. (https://doi.org/10.1016/j.ebiom.2016.07.034)

Rajeev SP \& Wilding J 2016 GLP-1 as a target for therapeutic intervention. Current Opinion in Pharmacology 31 44-49. (https://doi.org/10.1016/j. coph.2016.08.005)

Rizzo M, Chandalia M, Patti AM, Di Bartolo V, Rizvi AA, Montalto G \& Abate N 2014 Liraglutide decreases carotid intima-media thickness in patients with type 2 diabetes: 8-month prospective pilot study. Cardiovascular Diabetology 13 49. (https://doi.org/10.1186/1475-284013-49)

Secher A, Jelsing J, Baquero AF, Hecksher-Sorensen J, Cowley MA, Dalboge LS, Hansen G, Grove KL, Pyke C, Raun K, et al. 2014 The arcuate nucleus mediates GLP-1 receptor agonist liraglutidedependent weight loss. Journal of Clinical Investigation 124 4473-4488. (https://doi.org/10.1172/JCI75276)

Shadid S, Koutsari C \& Jensen MD 2007 Direct free fatty acid uptake into human adipocytes in vivo: relation to body fat distribution. Diabetes 56 1369-1375. (https://doi.org/10.2337/db06-1680) 
Sivertsen J, Rosenmeier J, Holst JJ \& Vilsboll T 2012 The effect of glucagon-like peptide 1 on cardiovascular risk. Nature Reviews Cardiology 9 209-222. (https://doi.org/10.1038/nrcardio.2011.211)

Taher J, Baker CL, Cuizon C, Masoudpour H, Zhang R, Farr S, Naples M, Bourdon C, Pausova Z \& Adeli K 2014 GLP-1 receptor agonism ameliorates hepatic VLDL overproduction and de novo lipogenesis in insulin resistance. Molecular Metabolism 3 823-833. (https://doi. org/10.1016/j.molmet.2014.09.005)

Tanaka K, Masaki Y, Tanaka M, Miyazaki M, Enjoji M, Nakamuta M, Kato M, Nomura M, Inoguchi T, Kotoh K, et al. 2014 Exenatide improves hepatic steatosis by enhancing lipid use in adipose tissue in nondiabetic rats. World Journal of Gastroenterology 20 2653-2663. (https://doi.org/10.3748/wjg.v20.i10.2653)

Tchkonia T, Thomou T, Zhu Y, Karagiannides I, Pothoulakis C, Jensen MD \& Kirkland JL 2013 Mechanisms and metabolic implications of regional differences among fat depots. Cell Metabolism 17 644-656. (https://doi.org/10.1016/j.cmet.2013.03.008)

Vella A \& Rizza RA 2009 Application of isotopic techniques using constant specific activity or enrichment to the study of carbohydrate metabolism. Diabetes 58 2168-2174. (https://doi.org/10.2337/db09-0318)

Verhoef SP, van Dijk P \& Westerterp KR 2013 Relative shrinkage of adipocytes by paraffin in proportion to plastic embedding in human adipose tissue before and after weight loss. Obesity
Research and Clinical Practice 7 e8-e13. (https://doi.org/10.1016/j. orcp.2012.03.001)

Wan Y, Bao X, Huang J, Zhang X, Liu W, Cui Q, Jiang D, Wang Z, Liu R \& Wang Q 2017 Novel GLP-1 analog supaglutide reduces HFD-induced obesity associated with increased Ucp-1 in white adipose tissue in mice. Frontiers in Physiology 8 294. (https://doi. org/10.3389/fphys.2017.00294)

White UA \& Tchoukalova YD 2014 Sex dimorphism and depot differences in adipose tissue function. Biochimica et Biophysica Acta 1842 377-392. (https://doi.org/10.1016/j. bbadis.2013.05.006)

Wing RR, Lang W, Wadden TA, Safford M, Knowler WC, Bertoni AG, Hill JO, Brancati FL, Peters A, Wagenknecht L, et al. 2011 Benefits of modest weight loss in improving cardiovascular risk factors in overweight and obese individuals with type 2 diabetes. Diabetes Care 34 1481-1486. (https://doi.org/10.2337/dc10-2415)

Wu J, Jun H \& McDermott JR 2015 Formation and activation of thermogenic fat. Trends in Genetics 31 232-238. (https://doi. org/10.1016/j.tig.2015.03.003)

Zhao L, Cang Z, Sun H, Nie X, Wang N \& Lu Y 2017 Berberine improves glucogenesis and lipid metabolism in nonalcoholic fatty liver disease. BMC Endocrine Disorders 17 13. (https://doi.org/10.1186/s12902-0170165-7)

Received in final form 19 October 2018

Accepted 8 November 2018 (c) 2019 Society for Endocrinology Published by Bioscientifica Ltd. 